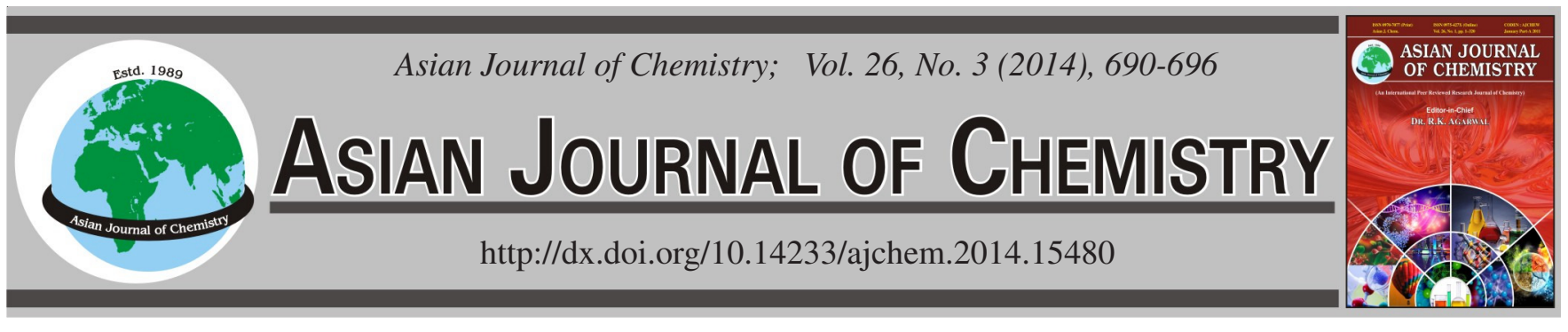

\title{
Synthesis, Characterization and Antibacterial Study of 7-O-Substituted Derivatives of Chlorinated Coumarin
}

\author{
Shahid Rasool ${ }^{1}$, Aziz-ur-Rehman ${ }^{1, *}$, Muhammad Athar Abbasi ${ }^{1}$, Khadija Nafeesa $^{1}$, \\ Asia Siddiqa ${ }^{1}$, Ghulam Hussain ${ }^{1}$, Irshad Ahmad ${ }^{2}$ and Shafia Arshad ${ }^{2}$
}

${ }^{1}$ Department of Chemistry, Government College University, Lahore, Pakistan
${ }^{2}$ Department of Pharmacy, Faculty of Pharmacy and Alternative Medicine, The Islamia University of Bahawalpur, Bahawalpur, Pakistan

*Corresponding author: Tel: +92 42 111000010, Ext. 450; E-mail: azizryk@yahoo.com

Received: 14 March 2013;

Accepted: 8 May 2013;

Published online: 30 January 2014;

AJC-14616

\begin{abstract}
In this research work, a series of 7-O-alkyl/aralkyl/acyl substituted derivatives of chlorinated coumarin was synthesized and screened for their antibacterial activity. The parent compound 6-chloro-7-hydroxy-4-methyl-2H-chromen-2-one (3) was prepared by the coupling of homogeneous mixing of 4-chlororesorcinol (1) and ethylacetoacetate (2) in a conc. $\mathrm{H}_{2} \mathrm{SO}_{4}$ medium. Further, the 7-O-substituted derivatives of coumarins $\mathbf{5 a - i}$ and $\mathbf{7} \mathbf{a}-\mathbf{h}$ were prepared by the reaction of parent compound with different alkyl/aralkyl/acyl halides $\mathbf{4 a - i}$ and $\mathbf{6} \mathbf{a}-\mathbf{h}$. The synthesized compounds were supported via spectral data. The prepared compounds were evaluated for inhibition activity against bacterial strains including Gram-positive and Gram-negative and were observed that some of the compounds exhibited activity to varying degree.
\end{abstract}

Keywords: 4-Chlororesorcinol, Chlorinated coumarin, Antibacterial activity, ${ }^{1} \mathrm{H}$ NMR, ${ }^{13} \mathrm{C}$ NMR and EI-MS.

\section{INTRODUCTION}

Coumarins belong to a huge heterocyclic family and detected in plants like tonka bean etc. Coumarin heterocyclic nucleus and their innumerous derivatives possess the potential biological activity. These are familiar due to various activities like antiinflammatory, vasodilator etc. ${ }^{1-8}$. Rutaceae plants exhibit antimicrobial activity credibly because of coumarins which are pharmacologically important ${ }^{9}$. Coumarin derivatives have remarkable antimicrobial properties and this encouraged us to synthesize coumarin derivatives as potential agents.

In continuation of our previous work of $O$-substituted derivatives ${ }^{10}$, the synthesis of 7-O-alkyl/aralkyl/acyl substituted derivatives of chlorinated coumarins was carried out with an objective to detect the in vitro antibacterial activity against Gram-positive and Gram-negative bacteria using standard procedure. The present research effort was a successful attempt to find out biologically active compounds.

\section{EXPERIMENTAL}

4-Chlororesorcinol, ethylacetoacetate and alkyl/acyl halides were purchased from Merck and Alfa Aeser through local suppliers and were processed further as supplied. The analytical grade solvents were utilized for the research work. Thin layer chromatography (TLC) with solvent systems of ethyl acetate and $n$-hexane was a valuable tool for analyzing the purity. TLC plates were purchased from local supplier and visualized under $\mathrm{UV}_{254}$ accompanied by ceric sulfate solution. Infrared spectra was processed via $\mathrm{KBr}$ pellet method utilizing Jasco-320-A spectrophotometer $\left(\mathrm{cm}^{-1}\right)$. Melting points of the finalized compounds were entered with the help of GriffinGeorge melting point apparatus via open capillary along with uncorrection. Nuclear magnetic resonance spectra including ${ }^{1} \mathrm{H}$ and ${ }^{13} \mathrm{C}$ were put down in $\mathrm{CDCl}_{3}$ on a Bruker spectrometers operating at a frequency of 400 and $125 \mathrm{MHz}$ severally. The $\delta$-values are accounted in ppm with TMS reference and the $J$-values are presented in Hertz. EI-MS spectra were put down on a JMS-HX-110 spectrometer.

Synthesis of 6-chloro-7-hydroxy-4-methyl- $2 \mathrm{H}$-chromen2-one (3): 4-Chlororesorcinol (0.035 moles, 5 g, 1) was dissolved in ethylacetoacetate $(0.035 \mathrm{~mol}, 5.0 \mathrm{~mL}, 2)$ in a $500 \mathrm{~mL}$ iodine flask. $15 \mathrm{~mL}$ of conc. $\mathrm{H}_{2} \mathrm{SO}_{4}$ was added drop wise with continuous shaking keeping in a cool media and the contents were kept overnight. Precipitates of the product were generated by the addition of ice cold water to the reaction mixture. Precipitates were filtered off, washed up with excess cold water and dried up to acquire the required product 3 . Purity was observed by single spot on TLC plate. Recrystallization was carried out by using methanol.

General procedure for the synthesis of 6-chloro-7alkoxy/aralkoxy-4-methyl-2H-chromen-2-one (5a-i): The product $3(0.2 \mathrm{~g}, 0.00095 \mathrm{~mol})$ was thoroughly mixed in $5 \mathrm{~mL}$ 
of aprotic solvent DMF, followed by addition of a base $\mathrm{LiH}$ $(0.006 \mathrm{~g}, 0.00095 \mathrm{~mol})$ in a $50 \mathrm{~mL}$ round bottom flask and stirred for $20 \mathrm{~min}$. After that the addition of alkyl/aralkyl halides (4a-i) was processed following the stirring for 3-4 h. Reaction completion was tracked via TLC. The formation of precipitates was achieved through the addition of distilled water and were filtered off, washed up with cold distilled water and finally dried up to collect the synthesized products, $\mathbf{5 a - i}$.

General procedure for the synthesis of 6-chloro-7alkanoyloxy-4-methyl-2H-chromen-2-one (7a-h): The product $3(1.00 \mathrm{~g}, 0.005 \mathrm{~mol})$ was taken in a $250 \mathrm{~mL}$ round bottom flask followed by the addition of distilled water. To make it soluble, solution of $10 \% \mathrm{NaOH}$ was added drop wise with gradual stirring until clear solution was obtained. Then acyl halides $(0.005 \mathrm{~mol}, \mathbf{6} \mathbf{a}-\mathbf{h})$ were added and the contents were stirred for $25 \mathrm{~min}$. TLC was used up to check out the reaction completion. The formed precipitates were filtered off, washed up with cold distilled water and dried up to get the synthesized compounds, 7a-h.

Antibacterial activity assay: 96-wells microplates were used for antimicrobial activity assay after sterilization and also in sterile conditions. The basic principle of increase in number of cells in a log phase of microbial growth resulting in increment in absorbance in the broth medium is applied ${ }^{11,12}$. The bacterial strains of Gram-positive and Gram-negative bacteria were taken into account. The bacteria were grown in agar culture medium. Twenty $\mu \mathrm{g}$ of the samples diluted by suited solvents were introduced into each well. The fresh maintained culture was also introduced into each well to make a volume of $200 \mu \mathrm{L}$ after suited dilution with fresh nutrient broth. The incubation of culture having lid on the micro plate was performed at $37^{\circ} \mathrm{C}$ for 1 day. The absorbance was observed at $540 \mathrm{~nm}$ before (maintained between 0.12-0.19) and after incubation using micro plate reader. The difference in absorbance was an indicator of bacterial growth. The differences were compared with the reference standards i.e. ampicillin and ciprofloxacin. The percentage inhibition was computed by applying the formula,

$$
\text { Inhibition }(\%)=\frac{\text { Control }- \text { Test }}{\text { Control }} \times 100
$$

where Control $=$ Absorbance in control with bacterial culture, Test $=$ Absorbance in test sample.

Minimum inhibitory concentration (MIC) was calculated by using different dilutions (ranging 5-30 $\mu \mathrm{g} /$ well) and EZFit Perrella Scientific Inc. Amherst USA software.

Statistical analysis: The results are written as mean \pm sem after performance in three-folds and statistical analysis by Microsoft Excel 2010.

\section{Spectral characterization of the synthesized compounds}

6-Chloro-7-hydroxy-4-methyl-2H-chromen-2-one (3): Light brown amorphous solid; yield: $78 \%$; m.p. $277-279^{\circ} \mathrm{C}$; m.f.: $\mathrm{C}_{10} \mathrm{H}_{7} \mathrm{O}_{3} \mathrm{Cl}$; m.w.: $210 \mathrm{~g} \mathrm{~mol}^{-1}$; IR $\left(\mathrm{KBr}, \mathrm{v}_{\max }, \mathrm{cm}^{-1}\right): 3056$ (C-H aromatic stretching), 1720 (stretching of $\alpha, \beta$-unsaturated $\mathrm{C}=\mathrm{O}), 1625$ ( $\mathrm{C}=\mathrm{C}$ stretching of aromatic ring $) ;{ }^{1} \mathrm{H}$ NMR (400 $\left.\mathrm{MHz}, \mathrm{CDCl}_{3}, \mathrm{ppm}\right): \delta 7.54$ (s, 1H, H-5), 6.98 (s, 1H, H-8), 6.17 (s, 1H, H-3), 2.37 (s, 3H, $\left.\mathrm{CH}_{3}-11\right)$; ${ }^{13} \mathrm{C} \mathrm{NMR}(125 \mathrm{MHz}$, $\left.\mathrm{CDCl}_{3}, \mathrm{ppm}\right): \delta 160.5$ (C-2), 157.7 (C-7), 153.4 (C-4), 151.5
(C-9), 125.4 (C-5), 118.7 (C-6), 113.6 (C-10), 112.7 (C-3), 100.3 (C-8), 18.5 (C-11); EIMS: $m / z 212[\mathrm{M}+2]^{+}, 210[\mathrm{M}]^{+}$,

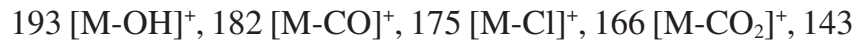
$\left[\mathrm{M}-\mathrm{CH}_{4} \mathrm{ClO}\right]^{+}, 134\left[\mathrm{M}-\mathrm{C}_{2} \mathrm{HClO}\right]^{+}$.

6-Chloro-7-methoxy-4-methyl-2H-chromen-2-one (5a): Light pink amorphous solid; yield: $53 \%$; m.p. 142-144 ${ }^{\circ} \mathrm{C}$; m.f.: $\mathrm{C}_{11} \mathrm{H}_{9} \mathrm{O}_{3} \mathrm{Cl}$; m.w.: $224 \mathrm{~g} \mathrm{~mol}^{-1}$; IR (KBr, $\left.v_{\max }, \mathrm{cm}^{-1}\right)$ : 3057 (C-H aromatic stretching), 1721 (stretching of $\alpha, \beta$ unsaturated $\mathrm{C}=\mathrm{O}), 1627(\mathrm{C}=\mathrm{C}$ stretching of aromatic ring); ${ }^{1} \mathrm{H}$ NMR (400 MHz, $\left.\mathrm{CDCl}_{3}, \mathrm{ppm}\right): \delta 7.56$ (s, 1H, H-5), 6.85 (s, 1H, H-8), 6.16 (s, 1H, H-3), 3.95 (s, 3H, $\mathrm{CH}_{3}-1$ '), 2.37 (s, $\left.3 \mathrm{H}, \mathrm{CH}_{3}-11\right) ;{ }^{13} \mathrm{C} \mathrm{NMR}\left(125 \mathrm{MHz}, \mathrm{CDCl}_{3}, \mathrm{ppm}\right): \delta 160.6(\mathrm{C}-$ 2), 157.6 (C-7), 153.6 (C-4), 151.6 (C-9), 125.3 (C-5), 118.9 (C-6), 113.8 (C-10), 112.9 (C-3), 100.4 (C-8), 56.6 (C-1'), 18.6 (C-11); EIMS: m/z $226[\mathrm{M}+2]^{+}, 224\left[\mathrm{M}^{+}, 209[\mathrm{M}-\right.$ $\left.\mathrm{CH}_{3}\right]^{+}, 193\left[\mathrm{M}-\mathrm{OCH}_{3}\right]^{+}, 189[\mathrm{M}-\mathrm{Cl}]^{+}, 180\left[\mathrm{M}-\mathrm{CO}_{2}\right]^{+}, 143[\mathrm{M}-$ $\left.\mathrm{C}_{2} \mathrm{H}_{6} \mathrm{ClO}\right]^{+}, 134\left[\mathrm{M}-\mathrm{C}_{3} \mathrm{H}_{3} \mathrm{ClO}\right]^{+}$.

6-Chloro-7-(propan-1-yloxy)-4-methyl-2H-chromen2-one (5b): White amorphous solid; yield: $59 \%$; m.p. 128$130{ }^{\circ} \mathrm{C}$; m.f.: $\mathrm{C}_{13} \mathrm{H}_{13} \mathrm{O}_{3} \mathrm{Cl}$; m.w.: $252 \mathrm{~g} \mathrm{~mol}^{-1}$; IR (KBr, $v_{\max }$, $\left.\mathrm{cm}^{-1}\right)$ : 3055 (C-H aromatic stretching), 1719 (stretching of $\alpha, \beta$ unsaturated $\mathrm{C}=\mathrm{O}), 1624(\mathrm{C}=\mathrm{C}$ stretching of aromatic ring); ${ }^{1} \mathrm{H}$ NMR (400 MHz, $\left.\mathrm{CDCl}_{3}, \mathrm{ppm}\right): \delta 7.55$ (s, 1H, H-5), 6.82 (s, 1H, H-8), 6.16 (s, 1H, H-3), 3.99 (t, $J=7.2 \mathrm{~Hz}, 2 \mathrm{H}, \mathrm{H}-1$ '), 2.36 (s, 3H, $\left.\mathrm{CH}_{3}-11\right)$, 1.86-1.88 (m, 2H, H-2'), 1.07 (t, $J=6.8$ $\left.\mathrm{Hz}, 3 \mathrm{H}, \mathrm{CH}_{3}-3^{\prime}\right) ;{ }^{13} \mathrm{C}-\mathrm{NMR}\left(125 \mathrm{MHz}, \mathrm{CDCl}_{3}\right.$, ppm): $\delta 160.7$ (C-2), 157.1 (C-7), 153.5 (C-4), 151.7 (C-9), 125.2 (C-5), 119.2 (C-6), 113.7 (C-10), 112.6 (C-3), 101.0 (C-8), 71.01 (C-1'), 22.1 (C-2'), 18.6 (C-11), 10.4 (C-3'); EIMS: m/z 254

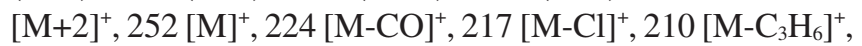
$193\left[\mathrm{M}-\mathrm{OC}_{3} \mathrm{H}_{7}\right]^{+}, 188\left[\mathrm{M}-\mathrm{CO}_{2}\right]^{+}, 143\left[\mathrm{M}-\mathrm{C}_{4} \mathrm{H}_{10} \mathrm{ClO}\right]^{+}, 134[\mathrm{M}-$ $\left.\mathrm{C}_{5} \mathrm{H}_{7} \mathrm{ClO}\right]^{+}$.

6-Chloro-7-(butan-1-yloxy)-4-methyl-2H-chromen-2one (5c): White amorphous solid; yield: $65 \%$; m.p. $130-132{ }^{\circ} \mathrm{C}$; m.f.: $\mathrm{C}_{14} \mathrm{H}_{15} \mathrm{O}_{3} \mathrm{Cl}$; m.w.: $266 \mathrm{~g} \mathrm{~mol}^{-1}$; IR $\left(\mathrm{KBr}, \mathrm{v}_{\max }, \mathrm{cm}^{-1}\right)$ : 3053 (C-H aromatic stretching), 1718 (stretching of $\alpha, \beta$-unsaturated $\mathrm{C}=\mathrm{O}), 1629\left(\mathrm{C}=\mathrm{C}\right.$ stretching of aromatic ring); ${ }^{1} \mathrm{H}$ NMR (400 $\mathrm{MHz}, \mathrm{CDCl}_{3}, \mathrm{ppm}$ ): $\delta 7.54$ (s, 1H, H-5), 6.82 (s, 1H, H-8), 6.14 (s, 1H, H-3), 4.06 (t, J = 6.4 Hz, 2H, H-1'), 2.36 (s, 3H, $\mathrm{CH}_{3}-11$ ), 1.84 (qui, $J=6.8 \mathrm{~Hz}, 2 \mathrm{H}, \mathrm{H}-2^{\prime}$ ), $1.48-1.51$ (m, $2 \mathrm{H}$, $\left.\mathrm{H}^{\prime} 3^{\prime}\right), 0.98$ (t, $\left.J=7.2 \mathrm{~Hz}, 3 \mathrm{H}, \mathrm{CH}_{3}-4{ }^{\prime}\right) ;{ }^{13} \mathrm{C} \mathrm{NMR}(125 \mathrm{MHz}$, $\left.\mathrm{CDCl}_{3}, \mathrm{ppm}\right): \delta 160.7$ (C-2), $157.2(\mathrm{C}-7), 153.6(\mathrm{C}-4), 151.6$ (C-9), 125.2 (C-5), 119.2 (C-6), 113.5 (C-10), 112.7 (C-3), 100.0 (C-8), 69.3 (C-1'), 30.7 (C-2'), 19.1 (C-3'), 18.6 (C-11), 13.7 (C-4'); EIMS: m/z $268[\mathrm{M}+2]^{+}, 266[\mathrm{M}]^{+}, 238[\mathrm{M}-\mathrm{CO}]^{+}$, $231[\mathrm{M}-\mathrm{Cl}]^{+}, 222\left[\mathrm{M}-\mathrm{CO}_{2}\right]^{+}, 212\left[\mathrm{M}-\mathrm{C}_{4} \mathrm{H}_{6}\right]^{+}, 210\left[\mathrm{M}-\mathrm{C}_{4} \mathrm{H}_{8}\right]^{+}$, $193\left[\mathrm{M}-\mathrm{OC}_{4} \mathrm{H}_{9}\right]^{+}, 143\left[\mathrm{M}-\mathrm{C}_{5} \mathrm{H}_{12} \mathrm{ClO}\right]^{+}, 134\left[\mathrm{M}-\mathrm{C}_{6} \mathrm{H}_{9} \mathrm{ClO}\right]^{+}$.

6-Chloro-7-(butan-2-yloxy)-4-methyl-2H-chromen-2one (5d): Light brown amorphous solid; yield: $71 \%$; m.p. 120-122 ${ }^{\circ} \mathrm{C}$; m.f.: $\mathrm{C}_{14} \mathrm{H}_{15} \mathrm{O}_{3} \mathrm{Cl}$; m.w.: $266 \mathrm{~g} \mathrm{~mol}^{-1}$; IR (KBr, $\left.v_{\max }, \mathrm{cm}^{-1}\right): 3060(\mathrm{C}-\mathrm{H}$ aromatic stretching), 1725 (stretching of $\alpha, \beta$-unsaturated $\mathrm{C}=\mathrm{O}), 1626(\mathrm{C}=\mathrm{C}$ stretching of aromatic ring); ${ }^{1} \mathrm{H}$ NMR (400 MHz, $\left.\mathrm{CDCl}_{3}, \mathrm{ppm}\right): \delta 7.55$ (s, $\left.1 \mathrm{H}, \mathrm{H}-5\right)$, 6.82 (s, 1H, H-8), 6.13 (s, 1H, H-3), 4.35-4.40 (m, 1H, H-1'), 2.36 (s, 3H, $\left.\mathrm{CH}_{3}-11\right), 1.36\left(\mathrm{~d}, J=6.0 \mathrm{~Hz}, 3 \mathrm{H}, \mathrm{CH}_{3}-4\right.$ '), $1.21-$ 1.30 (m, 2H, H-2'), 0.98 (t, $\left.J=7.2 \mathrm{~Hz}, 3 \mathrm{H}, \mathrm{CH}_{3}-3^{\prime}\right)$; ${ }^{13} \mathrm{C} \mathrm{NMR}$ (125 MHz, $\left.\mathrm{CDCl}_{3}, \mathrm{ppm}\right): \delta 160.5$ (C-2), 157.3 (C-7), 153.7 (C-4), 151.5 (C-9), 125.3 (C-5), 119.1 (C-6), 113.3 (C-10), 
112.6 (C-3), 100.1 (C-8), 70.3 (C-1'), 31.5 (C-2'), 20.3 (C-4'), 18.7 (C-11), 10.7 (C-3'); EIMS: $m / z 268[\mathrm{M}+2]^{+}, 266[\mathrm{M}]^{+}$, $238[\mathrm{M}-\mathrm{CO}]^{+}, 231[\mathrm{M}-\mathrm{Cl}]^{+}, 222\left[\mathrm{M}-\mathrm{CO}_{2}\right]^{+}, 212\left[\mathrm{M}-\mathrm{C}_{4} \mathrm{H}_{6}\right]^{+}$, $210\left[\mathrm{M}-\mathrm{C}_{4} \mathrm{H}_{8}\right]^{+}, 193\left[\mathrm{M}-\mathrm{OC}_{4} \mathrm{H}_{9}\right]^{+}, 143\left[\mathrm{M}-\mathrm{C}_{5} \mathrm{H}_{12} \mathrm{ClO}\right]^{+}, 134$ $\left[\mathrm{M}-\mathrm{C}_{6} \mathrm{H}_{9} \mathrm{ClO}\right]^{+}$

6-Chloro-7-(pentan-1-yloxy)-4-methyl-2H-chromen-2one (5e): Dark brown amorphous solid; yield: $53 \%$; m.p. 158$160{ }^{\circ} \mathrm{C}$; m.f.: $\mathrm{C}_{15} \mathrm{H}_{17} \mathrm{O}_{3} \mathrm{Cl}$; m.w.: $280 \mathrm{~g} \mathrm{~mol}^{-1}$; IR (KBr, $v_{\max }$, $\mathrm{cm}^{-1}$ ): 3052 (C-H aromatic stretching), 1724 (stretching of $\alpha, \beta$ unsaturated $\mathrm{C}=\mathrm{O}), 1623(\mathrm{C}=\mathrm{C}$ stretching of aromatic ring); ${ }^{1} \mathrm{H}$ NMR (400 MHz, $\left.\mathrm{CDCl}_{3}, \mathrm{ppm}\right): \delta 7.54$ (s, 1H, H-5), 6.82 (s, 1H, H-8), 6.14 (s, 1H, H-3), 4.06 (t, $J=6.8 \mathrm{~Hz}, 2 \mathrm{H}, \mathrm{H}-1$ '), 2.36 (s, 3H, $\mathrm{CH}_{3}-11$ ), 1.86 (qui, $J=6.8 \mathrm{~Hz}, 2 \mathrm{H}, \mathrm{H}-2$ '), 1.38 1.47 (m, 4H, H-3', H-4'), 0.93 (t, $\left.J=7.2 \mathrm{~Hz}, 3 \mathrm{H}, \mathrm{CH}_{3}-5^{\prime}\right) ;{ }^{13} \mathrm{C}$ NMR (125 MHz, $\mathrm{CDCl}_{3}$, ppm): $\delta 160.7$ (C-2), 157.2 (C-7), 153.6 (C-4), 151.6 (C-9), 125.2 (C-5), 119.2 (C-6), 113.5 (C10), 112.7 (C-3), 101.0 (C-8), 69.6 (C-1'), 28.4 (C-2'), 28.0 (C-3'), 22.3 (C-4'), 18.6 (C-11), 13.9 (C-5'); EIMS: m/z 282

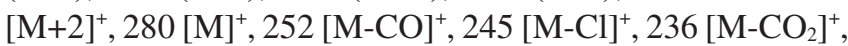
$226\left[\mathrm{M}-\mathrm{C}_{4} \mathrm{H}_{6}\right]^{+}, 224\left[\mathrm{M}-\mathrm{C}_{4} \mathrm{H}_{8}\right]^{+}, 193\left[\mathrm{M}-\mathrm{OC}_{5} \mathrm{H}_{11}\right]^{+}, 143[\mathrm{M}-$

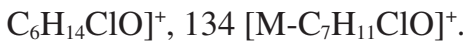

6-Chloro-7-(heptan-1-yloxy)-4-methyl-2H-chromen-2one (5f): Brown amorphous solid; yield: $62 \%$; m.p. 172-174 ${ }^{\circ} \mathrm{C}$; m.f.: $\mathrm{C}_{17} \mathrm{H}_{21} \mathrm{O}_{3} \mathrm{Cl}$; m.w.: $308 \mathrm{~g} \mathrm{~mol}^{-1}$; IR $\left(\mathrm{KBr}, v_{\max }, \mathrm{cm}^{-1}\right)$ : 3051 (C-H aromatic stretching), 1715 (stretching of $\alpha, \beta$ unsaturated $\mathrm{C}=\mathrm{O}), 1621(\mathrm{C}=\mathrm{C}$ stretching of aromatic ring); ${ }^{1} \mathrm{H}$ NMR (400 MHz, $\left.\mathrm{CDCl}_{3}, \mathrm{ppm}\right): \delta 7.54$ (s, 1H, H-5), 6.82 (s, 1H, H-8), 6.14 (s, 1H, H-3), 4.05 (t, $\left.J=5.6 \mathrm{~Hz}, 2 \mathrm{H}, \mathrm{H}-1^{\prime}\right)$, 2.36 ( $\left.\mathrm{s}, 3 \mathrm{H}, \mathrm{CH}_{3}-11\right)$, 1.82-1.86 (m, 4H, H-2', H-3'), 1.291.53 (m, 6H, H-4' to H-6'), 0.88 (t, $\left.J=7.2 \mathrm{~Hz}, 3 \mathrm{H}, \mathrm{CH}_{3}-7^{\prime}\right)$; ${ }^{13} \mathrm{C}-\mathrm{NMR}\left(125 \mathrm{MHz}, \mathrm{CDCl}_{3}, \mathrm{ppm}\right): \delta 160.6(\mathrm{C}-2), 157.1(\mathrm{C}-$ 7), 153.7 (C-4), 151.5 (C-9), 125.4 (C-5), 119.3 (C-6), 113.4 (C-10), 112.9 (C-3), 101.3 (C-8), 69.5 (C-1'), 28.3 (C-2'), 28.1 (C-3'), 26.3 (C-4'), 24.1 (C-5'), 21.0 (C-6'), 18.5 (C-11), 12.9 (C-7'); EIMS: $m / z 310[\mathrm{M}+2]^{+}, 308\left[\mathrm{M}^{+}, 280[\mathrm{M}-\mathrm{CO}]^{+}, 273\right.$ $[\mathrm{M}-\mathrm{Cl}]^{+}, 264\left[\mathrm{M}-\mathrm{CO}_{2}\right]^{+}, 254\left[\mathrm{M}-\mathrm{C}_{4} \mathrm{H}_{6}\right]^{+}, 252\left[\mathrm{M}-\mathrm{C}_{4} \mathrm{H}_{8}\right]^{+}, 193$ $\left[\mathrm{M}-\mathrm{OC}_{5} \mathrm{H}_{11}\right]^{+}, 143\left[\mathrm{M}-\mathrm{C}_{8} \mathrm{H}_{18} \mathrm{ClO}\right]^{+}, 134\left[\mathrm{M}-\mathrm{C}_{9} \mathrm{H}_{15} \mathrm{ClO}\right]^{+}$.

6-Chloro-7-((2-methylphenyl)methoxy)-4-methyl-2Hchromen-2-one (5g): Light brown amorphous solid; yield: 75 \%; m.p. 134- $136{ }^{\circ} \mathrm{C}$; m.f.: $\mathrm{C}_{18} \mathrm{H}_{15} \mathrm{O}_{3} \mathrm{Cl}$; m.w.: 314 g mol $^{-1}$; IR $\left(\mathrm{KBr}, v_{\max }, \mathrm{cm}^{-1}\right): 3056(\mathrm{C}-\mathrm{H}$ aromatic stretching $), 1723$ (stretching of $\alpha, \beta$-unsaturated $\mathrm{C}=\mathrm{O}), 1628(\mathrm{C}=\mathrm{C}$ stretching of aromatic ring); ${ }^{1} \mathrm{H}$ NMR (400 MHz, $\left.\mathrm{CDCl}_{3}, \mathrm{ppm}\right): \delta 7.57$ (s, 1H, H-5), 7.28-7.43 (m, 4H, H-3' to H-6'), 6.92 (s, 1H, H-8), 6.15 (s, 1H, H-3), 5.16 (s, 2H, H-7'), 2.39 (s, 3H, $\mathrm{CH}_{3}-$ 11), 2.37 (s, 3H, $\mathrm{CH}_{3}-8$ ) $){ }^{13} \mathrm{C} \mathrm{NMR}\left(125 \mathrm{MHz}, \mathrm{CDCl}_{3}, \mathrm{ppm}\right)$ : $\delta 160.6$ (C-2), 156.3 (C-7), 153.3 (C-4), 151.7 (C-9), 134.3 (C-1'), 131.3 (C-2'), 129.3 (C-3'), 128.1 (C-4'), 125.3 (C-5), 123.2 (C-5'), 122.0 (C-6'), 121.9 (C-6), 114.5 (C-10), 113.4 (C-3), 101.2 (C-8), 69.1 (C-7'), 22.7 (C-8'), 18.6 (C-11); EIMS: $\mathrm{m} / \mathrm{z} 316[\mathrm{M}+2]^{+}, 314[\mathrm{M}]^{+}, 286[\mathrm{M}-\mathrm{CO}]^{+}, 279[\mathrm{M}-\mathrm{Cl}]^{+}, 270$ $\left[\mathrm{M}-\mathrm{CO}_{2}\right]^{+}, 209\left[\mathrm{M}-\mathrm{C}_{8} \mathrm{H}_{9}\right]^{+}, 193\left[\mathrm{M}-\mathrm{OC}_{8} \mathrm{H}_{9}\right]^{+}, 143[\mathrm{M}-$ $\mathrm{C}_{9} \mathrm{H}_{12} \mathrm{ClO}^{+}, 134\left[\mathrm{M}-\mathrm{C}_{10} \mathrm{H}_{9} \mathrm{ClO}^{+}, 91\left[\mathrm{C}_{7} \mathrm{H}_{7}\right]^{+}, 79\left[\mathrm{C}_{6} \mathrm{H}_{7}\right]^{+}, 65\right.$ $\left[\mathrm{C}_{5} \mathrm{H}_{5}\right]^{+}, 51\left[\mathrm{C}_{4} \mathrm{H}_{3}\right]^{+}$.

6-Chloro-7-((2-bromophenyl)methoxy)-4-methyl-2Hchromen-2-one (5h): White amorphous solid; yield: $78 \%$; m.p. $110-112{ }^{\circ} \mathrm{C}$; m.f.: $\mathrm{C}_{17} \mathrm{H}_{12} \mathrm{O}_{3} \mathrm{BrCl}$; m.w.: 379 g mol $^{-1}$; IR $\left(\mathrm{KBr}, \mathrm{v}_{\max }, \mathrm{cm}^{-1}\right): 3050(\mathrm{C}-\mathrm{H}$ aromatic stretching), 1725 (stretching of $\alpha, \beta$-unsaturated $\mathrm{C}=\mathrm{O}), 1626(\mathrm{C}=\mathrm{C}$ stretching of aromatic ring); ${ }^{1} \mathrm{H}$ NMR (400 MHz, $\mathrm{CDCl}_{3}, \mathrm{ppm}$ ): $\delta 7.60$ (s, 1H, H-5), 7.57 (brs, 1H, H-3'), 7.55 (brs, 1H, H-6'), 7.34 (t, $\left.J=7.2 \mathrm{~Hz}, 1 \mathrm{H}, \mathrm{H}-5^{\prime}\right), 7.22$ (t, $J=7.2 \mathrm{~Hz}, 1 \mathrm{H}, \mathrm{H}-4$ '), 6.90 (s, 1H, H-8), 6.16 (s, 1H, H-3), 5.24 (s, 2H, H-7'), 2.37 (s, 3H, $\left.\mathrm{CH}_{3}-11\right) ;{ }^{13} \mathrm{C}$ NMR (125 MHz, $\left.\mathrm{CDCl}_{3}, \mathrm{ppm}\right): \delta 160.5$ (C-2), 156.2 (C-7), 153.4 (C-4), 151.5 (C-9), 134.5 (C-1'), 132.7 (C3'), 129.6 (C-6'), $128.6\left(\mathrm{C}-4^{\prime}\right), 127.7$ (C-5'), 125.5 (C-5), 121.9 (C-6), 119.3 (C-2'), 114.2 (C-10), 113.1 (C-3), 101.8 (C-8), 70.4 (C-7'), 18.6 (C-11); EIMS: m/z $383[\mathrm{M}+4]^{+}, 381[\mathrm{M}+2]^{+}$,

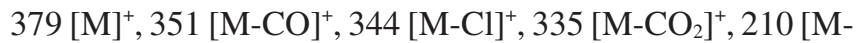
$\left.\mathrm{C}_{7} \mathrm{H}_{5} \mathrm{Br}\right]^{+}, 193\left[\mathrm{M}-\mathrm{OC}_{7} \mathrm{H}_{6} \mathrm{Br}\right]^{+}, 155\left[\mathrm{C}_{6} \mathrm{H}_{4} \mathrm{Br}\right]^{+}, 143\left[\mathrm{C}_{5} \mathrm{H}_{4} \mathrm{Br}\right]^{+}$, $134\left[\mathrm{M}-\mathrm{C}_{9} \mathrm{H}_{6} \mathrm{BrClO}\right]^{+}, 65\left[\mathrm{C}_{5} \mathrm{H}_{5}\right]^{+}, 51\left[\mathrm{C}_{4} \mathrm{H}_{3}\right]^{+}$.

6-Chloro-7-((3-bromophenyl)methoxy)-4-methyl-2Hchromen-2-one (5i): Dark pink amorphous solid; yield: 56 \%; m.p. 124-126 ${ }^{\circ} \mathrm{C}$; m.f.: $\mathrm{C}_{17} \mathrm{H}_{12} \mathrm{O}_{3} \mathrm{BrCl}$; m.w.: 379 g mol $^{-1}$; IR $\left(\mathrm{KBr}, \mathrm{v}_{\max }, \mathrm{cm}^{-1}\right): 3048(\mathrm{C}-\mathrm{H}$ aromatic stretching), 1721 (stretching of $\alpha, \beta$-unsaturated $\mathrm{C}=\mathrm{O}), 1626(\mathrm{C}=\mathrm{C}$ stretching of aromatic ring); ${ }^{1} \mathrm{H}$ NMR (400 MHz, $\mathrm{CDCl}_{3}, \mathrm{ppm}$ ): $\delta 7.60$ (s, 1H, H-5), 7.58 (s, 1H, H-2'), 7.46 (d, J = 7.6 Hz, 1H, H-6'), 7.37 (d, $J=7.6 \mathrm{~Hz}, 1 \mathrm{H}, \mathrm{H}-4$ '), 7.27 (d, $\left.J=8.0 \mathrm{~Hz}, 1 \mathrm{H}, \mathrm{H}-5^{\prime}\right)$, 6.85 (s, 1H, H-8), 6.16 (s, 1H, H-3), 5.16 (s, 2H, H-7'), 2.37 (s, 3H, $\left.\mathrm{CH}_{3}-11\right) ;{ }^{13} \mathrm{C}$ NMR (125 MHz, $\left.\mathrm{CDCl}_{3}, \mathrm{ppm}\right): \delta 160.4$ (C-2), 156.1 (C-7), 153.3 (C-4), 151.8 (C-9), 133.5 (C-1'), 132.1 (C-4'), 128.6 (C-5'), 127.9 (C-2'), 126.0 (C-6'), 125.7 (C-5), 122.3 (C-6), 118.2 (C-3'), 115.2 (C-10), 113.5 (C-3), 100.8 (C-8), 68.4 (C-7'), 18.3 (C-11); EIMS: m/z 383 [M+4] , $381[\mathrm{M}+2]^{+}, 379[\mathrm{M}]^{+}, 351[\mathrm{M}-\mathrm{CO}]^{+}, 344[\mathrm{M}-\mathrm{Cl}]^{+}, 335[\mathrm{M}-$ $\left.\mathrm{CO}_{2}\right]^{+}, 210\left[\mathrm{M}-\mathrm{C}_{7} \mathrm{H}_{5} \mathrm{Br}\right]^{+}, 193\left[\mathrm{M}-\mathrm{OC}_{7} \mathrm{H}_{6} \mathrm{Br}\right]^{+}, 155\left[\mathrm{C}_{6} \mathrm{H}_{4} \mathrm{Br}\right]^{+}$, $143\left[\mathrm{C}_{5} \mathrm{H}_{4} \mathrm{Br}\right]^{+}, 134\left[\mathrm{M}-\mathrm{C}_{9} \mathrm{H}_{6} \mathrm{BrClO}^{+}, 65\left[\mathrm{C}_{5} \mathrm{H}_{5}\right]^{+}, 51\left[\mathrm{C}_{4} \mathrm{H}_{3}\right]^{+}\right.$.

6-Chloro-4-methyl-2-oxo-2H-chromen-7-yl acetate (7a): Light pink amorphous solid; yield: 79 \%; m.p. 164-166 ${ }^{\circ} \mathrm{C}$; m.f.: $\mathrm{C}_{12} \mathrm{H}_{9} \mathrm{O}_{4} \mathrm{Cl}$; m.w.: $252 \mathrm{~g} \mathrm{~mol}^{-1}$; IR $\left(\mathrm{KBr}, v_{\max }, \mathrm{cm}^{-1}\right)$ : 3046 (C-H aromatic stretching), $1740(\mathrm{C}=\mathrm{O}$ stretching of ester), 1725 (stretching of $\alpha, \beta$-unsaturated $\mathrm{C}=\mathrm{O}), 1619(\mathrm{C}=\mathrm{C}$ stretching of aromatic ring); ${ }^{1} \mathrm{H} \mathrm{NMR}\left(400 \mathrm{MHz}, \mathrm{CDCl}_{3}, \mathrm{ppm}\right)$ : $\delta 7.53$ (s, 1H, H-5), 6.97 (s, 1H, H-8), 6.14 (s, 1H, H-3), 2.36 (s, 3H, $\left.\mathrm{CH}_{3}-11\right), 2.26$ (s, 3H, $\mathrm{CH}_{3}-1$ ) $;{ }^{13} \mathrm{C}$ NMR (125 MHz, $\left.\mathrm{CDCl}_{3}, \mathrm{ppm}\right): \delta 163.8$ (C-12), 160.3 (C-2), 157.3 (C-4), 153.4 (C-7), 151.8 (C-9), 125.1 (C-5), 118.7 (C-6), 113.5 (C-10), 112.2 (C-3), 100.3 (C-8), 23.0 (C-1'), 18.4 (C-11); EIMS: $\mathrm{m} / \mathrm{z}, 254[\mathrm{M}+2]^{+}, 252[\mathrm{M}]^{+}, 193\left[\mathrm{M}-\mathrm{C}_{2} \mathrm{H}_{3} \mathrm{O}_{2}\right]^{+}, 224[\mathrm{M}-\mathrm{CO}]^{+}$,

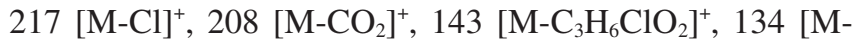
$\left.\mathrm{C}_{4} \mathrm{H}_{3} \mathrm{ClO}_{2}\right]^{+}$.

6-Chloro-4-methyl-2-oxo-2H-chromen-7-yl-2-bromoacetate (7b): Light brown amorphous solid; yield: $86 \%$; m.p. 192-194 ${ }^{\circ} \mathrm{C}$; m.f.: $\mathrm{C}_{12} \mathrm{H}_{8} \mathrm{O}_{4} \mathrm{BrCl}$; m.w.: $331 \mathrm{~g} \mathrm{~mol}^{-1}$; IR (KBr, $\left.V_{\max }, \mathrm{cm}^{-1}\right): 3049(\mathrm{C}-\mathrm{H}$ aromatic stretching $), 1744(\mathrm{C}=\mathrm{O}$ stretching of ester), 1723 (stretching of $\alpha_{2} \beta$-unsaturated $\mathrm{C}=\mathrm{O}$ ), 1621 $\left(\mathrm{C}=\mathrm{C}\right.$ stretching of aromatic ring); ${ }^{1} \mathrm{H} \mathrm{NMR}\left(400 \mathrm{MHz}, \mathrm{CDCl}_{3}\right.$, ppm): $\delta 7.52$ (s, 1H, H-5), 6.98 (s, 1H, H-8), 6.13 (s, 1H, $\mathrm{H}-3), 2.30$ (s, 3H, $\left.\mathrm{CH}_{3}-11\right), 3.68$ (s, 2H, H-1'); ${ }^{13} \mathrm{C}$ NMR (125 $\left.\mathrm{MHz}, \mathrm{CDCl}_{3}, \mathrm{ppm}\right): \delta 160.6(\mathrm{C}-2), 158.9(\mathrm{C}-12), 157.6(\mathrm{C}-4)$, 153.7 (C-7), 151.1 (C-9), 125.4 (C-5), 118.2 (C-6), 113.1 (C-10), 112.5 (C-3), 101.1 (C-8), 31.2 (C-1'), 18.2 (C-11); EIMS: $m / z, 335[\mathrm{M}+4]^{+}, 333[\mathrm{M}+2]^{+}, 331[\mathrm{M}]^{+}, 193[\mathrm{M}-$

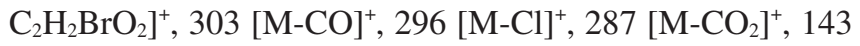
$\left[\mathrm{M}-\mathrm{C}_{3} \mathrm{H}_{5} \mathrm{BrClO}_{2}\right]^{+}, 134\left[\mathrm{M}-\mathrm{C}_{4} \mathrm{H}_{2} \mathrm{BrClO}_{2}\right]^{+}$. 
6-Chloro-4-methyl-2-oxo-2H-chromen-7-yl phenyl carbonate (7c): Dark brown amorphous solid; yield: $81 \%$; m.p. 246-248 ${ }^{\circ} \mathrm{C}$; m.f.: $\mathrm{C}_{17} \mathrm{H}_{11} \mathrm{O}_{5} \mathrm{Cl}$; m.w.: $330 \mathrm{~g} \mathrm{~mol}^{-1}$; IR (KBr, $\left.\mathrm{V}_{\max }, \mathrm{cm}^{-1}\right): 3055(\mathrm{C}-\mathrm{H}$ aromatic stretching $), 1750(\mathrm{C}=\mathrm{O}$ stretching of ester), 1727 (stretching of $\alpha, \beta$-unsaturated $\mathrm{C}=\mathrm{O}$ ), 1633 $(\mathrm{C}=\mathrm{C}$ stretching of aromatic ring $) ;{ }^{1} \mathrm{H} \mathrm{NMR}\left(400 \mathrm{MHz}, \mathrm{CDCl}_{3}\right.$, ppm): $\delta 7.59$ (s, 1H, H-5), 7.44 (t, $J=7.2 \mathrm{~Hz}, 2 \mathrm{H}, \mathrm{H}-3^{\prime}$ and H-5'), 7.37 (d, $J=7.2 \mathrm{~Hz}, 2 \mathrm{H}, \mathrm{H}-2^{\prime}$ and H-6'), 7.23-7.19 (m, 1H, H-4'), 6.98 (s, 1H, H-8), 6.13 (s, 1H, H-3), 2.30 (s, 3H, $\left.\mathrm{CH}_{3}-11\right) ;{ }^{13} \mathrm{C}-\mathrm{NMR}\left(125 \mathrm{MHz}, \mathrm{CDCl}_{3}, \mathrm{ppm}\right): \delta 160.8$ (C-2), 158.3 (C-7), 156.2 (C-4), 155.1 (C-9), 153.0 (C-1'), 151.4 (C-12), 134.1 (C-3' and C-5'), 132.7 (C-5), 128.5 (C-4'), 127.3 (C-6), 126.4 (C-2' and C-6'), 114.0 (C-10), 113.3 (C-8), 101.4 (C-3), 18.6 (C-11); EIMS: m/z $332[\mathrm{M}+2]^{+}, 330[\mathrm{M}]^{+}, 193$ $\left[\mathrm{M}-\mathrm{C}_{7} \mathrm{H}_{5} \mathrm{O}_{3}\right]^{+}, 302[\mathrm{M}-\mathrm{CO}]^{+}, 295[\mathrm{M}-\mathrm{Cl}]^{+}, 286\left[\mathrm{M}-\mathrm{CO}_{2}\right]^{+}, 143$ $\left[\mathrm{M}-\mathrm{C}_{8} \mathrm{H}_{8} \mathrm{ClO}_{3}\right]^{+}, 134\left[\mathrm{M}-\mathrm{C}_{9} \mathrm{H}_{5} \mathrm{ClO}_{3}\right]^{+}, 77\left[\mathrm{C}_{6} \mathrm{H}_{5}\right]^{+}$.

6-Chloro-4-methyl-2-oxo-2H-chromen-7-yl benzoate (7d): Light pink amorphous solid; yield: $81 \%$; m.p. 236-238 ${ }^{\circ} \mathrm{C}$; m.f.: $\mathrm{C}_{17} \mathrm{H}_{11} \mathrm{O}_{4} \mathrm{Cl}$; m.w.: $314 \mathrm{~g} \mathrm{~mol}^{-1}$; IR $\left(\mathrm{KBr}, \mathrm{v}_{\max }, \mathrm{cm}^{-1}\right)$ : 3041 (C-H aromatic stretching), $1749(\mathrm{C}=\mathrm{O}$ stretching of ester), 1733 (stretching of $\alpha, \beta$-unsaturated $\mathrm{C}=\mathrm{O}), 1631(\mathrm{C}=\mathrm{C}$ stretching of aromatic ring); ${ }^{1} \mathrm{H} \mathrm{NMR}\left(400 \mathrm{MHz}, \mathrm{CDCl}_{3}, \mathrm{ppm}\right)$ : $\delta 7.52(\mathrm{~s}, 1 \mathrm{H}, \mathrm{H}-5), 7.46\left(\mathrm{dd}, J=7.6,2.0 \mathrm{~Hz}, 2 \mathrm{H}, \mathrm{H}-2^{\prime}\right.$ and $\mathrm{H}-$ 6'), 7.39-7.37 (m, 3H, H-3' to H-5'), 6.98 (s, 1H, H-8), 6.13 (s, 1H, H-3), 2.30 (s, 3H, CH-11$) ;{ }^{13} \mathrm{C} \mathrm{NMR} \mathrm{(125} \mathrm{MHz,} \mathrm{CDCl}_{3}$, ppm): $\delta 160.6$ (C-2), 158.5 (C-12), 156.3 (C-4), 153.4 (C-7), 151.2 (C-9), 134.6 (C-4'), 131.1 (C-2' and C-6'), 128.2 (C-3' and C-5'), 126.9 (C-1'), 125.1 (C-5), 124.5 (C-6), 114.9 (C10), 113.1 (C-8), 103.2 (C-3), 18.4 (C-11); EIMS: m/z 316 $[\mathrm{M}+2]^{+}, 314[\mathrm{M}]^{+}, 193\left[\mathrm{M}-\mathrm{C}_{7} \mathrm{H}_{5} \mathrm{O}_{2}\right]^{+}, 286[\mathrm{M}-\mathrm{CO}]^{+}, 279[\mathrm{M}-$ $\mathrm{Cl}]^{+}, 270\left[\mathrm{M}-\mathrm{CO}_{2}\right]^{+}, 143\left[\mathrm{M}-\mathrm{C}_{8} \mathrm{H}_{8} \mathrm{ClO}_{2}\right]^{+}, 134\left[\mathrm{M}-\mathrm{C}_{9} \mathrm{H}_{5} \mathrm{ClO}_{2}\right]^{+}$, $77\left[\mathrm{C}_{6} \mathrm{H}_{5}\right]^{+}$.

6-Chloro-4-methyl-2-oxo-2H-chromen-7-yl 2-chlorobenzoate (7e): Light yellow amorphous solid; yield: $73 \%$; m.p. $258-260{ }^{\circ} \mathrm{C}$; m.f.: $\mathrm{C}_{17} \mathrm{H}_{10} \mathrm{O}_{4} \mathrm{Cl}_{2}$; m.w.: $349 \mathrm{~g} \mathrm{~mol}^{-1}$; IR ( $\mathrm{KBr}$, $\left.v_{\max }, \mathrm{cm}^{-1}\right): 3059(\mathrm{C}-\mathrm{H}$ aromatic stretching $), 1743(\mathrm{C}=\mathrm{O}$ stretching of ester), 1737 (stretching of $\alpha, \beta$-unsaturated $C=O$ ), 1641 $(\mathrm{C}=\mathrm{C}$ stretching of aromatic ring $) ;{ }^{1} \mathrm{H} \mathrm{NMR}\left(400 \mathrm{MHz}, \mathrm{CDCl}_{3}\right.$, ppm): $\delta 7.73$ (dd, $J=7.6,1.6 \mathrm{~Hz}, 1 \mathrm{H}, \mathrm{H}-3$ ') 7.59 (s, 1H, H-5), $7.51\left(\mathrm{t}, J=7.6 \mathrm{~Hz}, 1 \mathrm{H}, \mathrm{H}-4{ }^{\prime}\right), 7.47$ (dd, $J=7.6,1.6 \mathrm{~Hz}, 1 \mathrm{H}, \mathrm{H}-$ 6'), 7.40 (t, $J=7.6 \mathrm{~Hz}, 1 \mathrm{H}, \mathrm{H}-5$ '), 6.93 (s, 1H, H-8), 6.14 (s, 1H, H-3), 2.36 (s, 3H, CH $3-11) ;{ }^{13} \mathrm{C} \mathrm{NMR} \mathrm{(125} \mathrm{MHz,} \mathrm{CDCl}_{3}$, ppm): $\delta 160.3$ (C-2), 158.6 (C-12), 156.4 (C-4), 153.7 (C-7), 151.6 (C-9), 134.2 (C-2'), 132.0 (C-4'), 129.9 (C-1'), 128.3 (C-3'), 127.8 (C-5'), 126.5 (C-6'), 125.3 (C-5), 123.5 (C-6), 114.1 (C-10), 113.7 (C-8), 101.3 (C-3), 18.8 (C-11); EIMS: $\mathrm{m} / \mathrm{z} 353[\mathrm{M}+4]^{+}, 351[\mathrm{M}+2]^{+}, 349[\mathrm{M}]^{+}, 193\left[\mathrm{M}-\mathrm{C}_{7} \mathrm{H}_{4} \mathrm{ClO}_{2}\right]^{+}$, $321[\mathrm{M}-\mathrm{CO}]^{+}, 313[\mathrm{M}-\mathrm{Cl}]^{+}, 305\left[\mathrm{M}-\mathrm{CO}_{2}\right]^{+}, 143[\mathrm{M}-$ $\left.\mathrm{C}_{8} \mathrm{H}_{7} \mathrm{Cl}_{2} \mathrm{O}_{2}\right]^{+}, 134\left[\mathrm{M}-\mathrm{C}_{9} \mathrm{H}_{4} \mathrm{Cl}_{2} \mathrm{O}_{2}\right]^{+}, 77\left[\mathrm{C}_{6} \mathrm{H}_{5}\right]^{+}$.

6-Chloro-4-methyl-2-oxo-2H-chromen-7-yl 2,4dichlorobenzoate (7f): White amorphous solid; yield: $81 \%$; m.p. 272-274 ${ }^{\circ} \mathrm{C}$; m.f.: $\mathrm{C}_{17} \mathrm{H}_{9} \mathrm{O}_{4} \mathrm{Cl}_{3}$; m.w.: $383 \mathrm{~g} \mathrm{~mol}^{-1}$; IR ( $\mathrm{KBr}$, $\left.\nu_{\max }, \mathrm{cm}^{-1}\right): 3049(\mathrm{C}-\mathrm{H}$ aromatic stretching $), 1745(\mathrm{C}=\mathrm{O}$ stretching of ester), 1747 (stretching of $\alpha, \beta$-unsaturated $\mathrm{C}=\mathrm{O}$ ), 1646 $\left(\mathrm{C}=\mathrm{C}\right.$ stretching of aromatic ring); ${ }^{1} \mathrm{H} \mathrm{NMR}\left(400 \mathrm{MHz}, \mathrm{CDCl}_{3}\right.$, ppm): $\delta 7.87$ (d, J=1.6 Hz, 1H, H-3'), 7.63 (s, 1H, H-5), 7.47 $\left(\mathrm{d}, J=7.2 \mathrm{~Hz}, 1 \mathrm{H}, \mathrm{H}-6\right.$ ') 7.41 (dd, $\left.J=7.2,1.6 \mathrm{~Hz}, 1 \mathrm{H}, \mathrm{H}-5^{\prime}\right)$, 6.91 (s, 1H, H-8), 6.17 (s, 1H, H-3), 2.33 (s, 3H, $\left.\mathrm{CH}_{3}-11\right) ;{ }^{13} \mathrm{C}$
NMR (125 MHz, $\left.\mathrm{CDCl}_{3}, \mathrm{ppm}\right): \delta 160.4$ (C-2), 158.2 (C-12), 156.7 (C-4), 153.1 (C-7), 151.9 (C-9), 134.3 (C-4'), 132.5 (C2'), 129.3 (C-6'), 128.2 (C-1'), 127.5 (C-5'), 126.2 (C-3'), 125.1 (C-5), 123.6 (C-6), 114.3 (C-10), 113.5 (C-8), 101.2 (C-3), 18.4 (C-11); EIMS: m/z $389[\mathrm{M}+6]^{+}, 387[\mathrm{M}+4]^{+}, 385[\mathrm{M}+2]^{+}$,

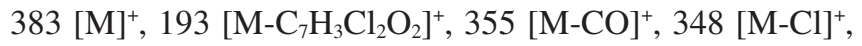
$339\left[\mathrm{M}-\mathrm{CO}_{2}\right]^{+}, 143\left[\mathrm{M}-\mathrm{C}_{8} \mathrm{H}_{6} \mathrm{Cl}_{3} \mathrm{O}_{2}\right]^{+}, 134\left[\mathrm{M}-\mathrm{C}_{9} \mathrm{H}_{3} \mathrm{Cl}_{3} \mathrm{O}_{2}\right]^{+}, 77$ $\left[\mathrm{C}_{6} \mathrm{H}_{5}\right]^{+}$.

6-Chloro-4-methyl-2-oxo-2H-chromen-7-yl thiophene2-carboxylate (7g): Light grey amorphous solid; yield: 78 \%; m.p. 266-268 ${ }^{\circ} \mathrm{C}$; m.f.: $\mathrm{C}_{15} \mathrm{H}_{9} \mathrm{O}_{4} \mathrm{SCl}$; m.w.: $320 \mathrm{~g} \mathrm{~mol}^{-1}$; IR $\left(\mathrm{KBr}, \mathrm{v}_{\max }, \mathrm{cm}^{-1}\right): 3062(\mathrm{C}-\mathrm{H}$ aromatic stretching), $1751(\mathrm{C}=\mathrm{O}$ stretching of ester), 1735 (stretching of $\alpha, \beta$-unsaturated $\mathrm{C}=\mathrm{O}$ ), $1650(\mathrm{C}=\mathrm{C}$ stretching of aromatic ring $) ;{ }^{1} \mathrm{H}-\mathrm{NMR}(400 \mathrm{MHz}$, $\mathrm{CDCl}_{3}, \mathrm{ppm}$ ): $\delta 7.69\left(\mathrm{dd}, J=7.2,1.2 \mathrm{~Hz}, 1 \mathrm{H}, \mathrm{H}-5^{\prime}\right), 7.59$ (s, $1 \mathrm{H}, \mathrm{H}-5), 7.47$ (t, $J=7.6 \mathrm{~Hz}, 1 \mathrm{H}, \mathrm{H}-4$ '), 7.35 (dd, $J=7.2,1.2$ Hz, 1H, H-3'), 6.98 (s, 1H, H-8), 6.17 (s, 1H, H-3), 2.38 (s, $\left.3 \mathrm{H}, \mathrm{CH}_{3}-11\right) ;{ }^{13} \mathrm{C} \mathrm{NMR}\left(125 \mathrm{MHz}, \mathrm{CDCl}_{3}, \mathrm{ppm}\right): \delta 160.3(\mathrm{C}-$ 2), 158.3 (C-12), 157.7 (C-7), 153.2 (C-4), 151.9 (C-9), 134.0 (C-2'), 131.2 (C-5'), 129.5 (C-3'), 128.1 (C-4'), 125.2 (C-5), 118.5 (C-6), 113.2 (C-10), 112.4 (C-8), 100.3 (C-3), 18.4 (C11); EIMS: $m / z, 322[\mathrm{M}+2]^{+}, 320[\mathrm{M}]^{+}, 193\left[\mathrm{M}-\mathrm{C}_{5} \mathrm{H}_{3} \mathrm{O}_{2} \mathrm{~S}\right]^{+}$, $292[\mathrm{M}-\mathrm{CO}]^{+}, 285[\mathrm{M}-\mathrm{Cl}]^{+}, 276\left[\mathrm{M}-\mathrm{CO}_{2}\right]^{+}, 143[\mathrm{M}-$ $\left.\mathrm{C}_{6} \mathrm{H}_{6} \mathrm{ClO}_{2} \mathrm{~S}\right]^{+}, 134\left[\mathrm{M}-\mathrm{C}_{7} \mathrm{H}_{3} \mathrm{ClO}_{2} \mathrm{~S}^{+}\right.$.

6-Chloro-4-methyl-2-oxo-2H-chromen-7-yl morpholine-4-carboxylate (7h): Grey amorphous solid; yield: $84 \%$; m.p. $232-234{ }^{\circ} \mathrm{C}$; m.f.: $\mathrm{C}_{15} \mathrm{H}_{14} \mathrm{NO}_{5} \mathrm{Cl}$; m.w.: $323 \mathrm{~g}$ $\mathrm{mol}^{-1}$; IR (KBr, $\left.v_{\max }, \mathrm{cm}^{-1}\right): 3054$ (C-H aromatic stretching), $1749(\mathrm{C}=\mathrm{O}$ stretching of ester), 1729 (stretching of $\alpha, \beta$-unsaturated $\mathrm{C}=\mathrm{O}), 1632(\mathrm{C}=\mathrm{C}$ stretching of aromatic ring $) ;{ }^{1} \mathrm{H}$ NMR (400 MHz, $\left.\mathrm{CDCl}_{3}, \mathrm{ppm}\right): \delta 7.54$ (s, 1H, H-5), 6.93 (s, $1 \mathrm{H}, \mathrm{H}-8), 6.15$ (s, 1H, H-3), 3.96 (t, $J=4.8 \mathrm{~Hz}, 4 \mathrm{H}, \mathrm{H}-2^{\prime}$ and H-6'), 2.96 (t, $J=4.8 \mathrm{~Hz}, 4 \mathrm{H}, \mathrm{H}-3^{\prime}$ and H-5'), 2.33 (s, 3H, $\left.\mathrm{CH}_{3}-11\right) ;{ }^{13} \mathrm{C}$ NMR $\left(125 \mathrm{MHz}, \mathrm{CDCl}_{3}, \mathrm{ppm}\right): \delta 160.6(\mathrm{C}-2)$, 157.6 (C-7), 153.6 (C-4), 151.6 (C-9), 149.6 (C-12), 125.3 (C-5), 118.9 (C-6), 113.8 (C-10), 112.9 (C-8), 100.4 (C-3), 69.9 (C-3' and C-5'), 39.2 (C-2' and C-6'), 18.6 (C-11); EIMS: $\mathrm{m} / \mathrm{z}, 325[\mathrm{M}+2]^{+}, 323[\mathrm{M}]^{+}, 193\left[\mathrm{M}-\mathrm{C}_{5} \mathrm{H}_{8} \mathrm{NO}_{3}\right]^{+}, 295[\mathrm{M}-\mathrm{CO}]^{+}$, $288[\mathrm{M}-\mathrm{Cl}]^{+}, 279\left[\mathrm{M}-\mathrm{CO}_{2}\right]^{+}, 143\left[\mathrm{M}-\mathrm{C}_{6} \mathrm{H}_{11} \mathrm{ClNO}_{3}\right]^{+}, 134[\mathrm{M}-$ $\left.\mathrm{C}_{7} \mathrm{H}_{8} \mathrm{ClNO}_{3}\right]^{+}$.

\section{RESULTS AND DISCUSSION}

The 7-O-alkyl/aralkyl/acyl substituted derivatives of chlorinated coumarins, $\mathbf{5} \mathbf{a}-\mathbf{i}$ and $\mathbf{7 a - h}$ were synthesized according to the protocol sketched in Scheme-I. The general reaction conditions and the structure characterization are already described.

The purpose of the undertaken research work was to introduce a series of new derivatives of chlorinated coumarin supported by antibacterial activity. The synthesis was carried out by the homogeneous intermixing of 4-chlororesorcinol (1) with ethylacetoacetate (2) in a strong acidic medium of conc. $\mathrm{H}_{2} \mathrm{SO}_{4}$. The homogeneous mixture was kept still for 10$12 \mathrm{~h}$ in the acidic medium. The solid product $\mathbf{3}$ was collected through filtration after the addition of ice cold water. Further, the compound $\mathbf{3}$ was treated with different alkyl/aralkyl halides as electrophiles, $\mathbf{4 a - j}$, to afford the products, $\mathbf{5} \mathbf{a}-\mathbf{j}$, with the help of $\mathrm{NaH}$ as weak base and aprotic polar solvent DMF. 


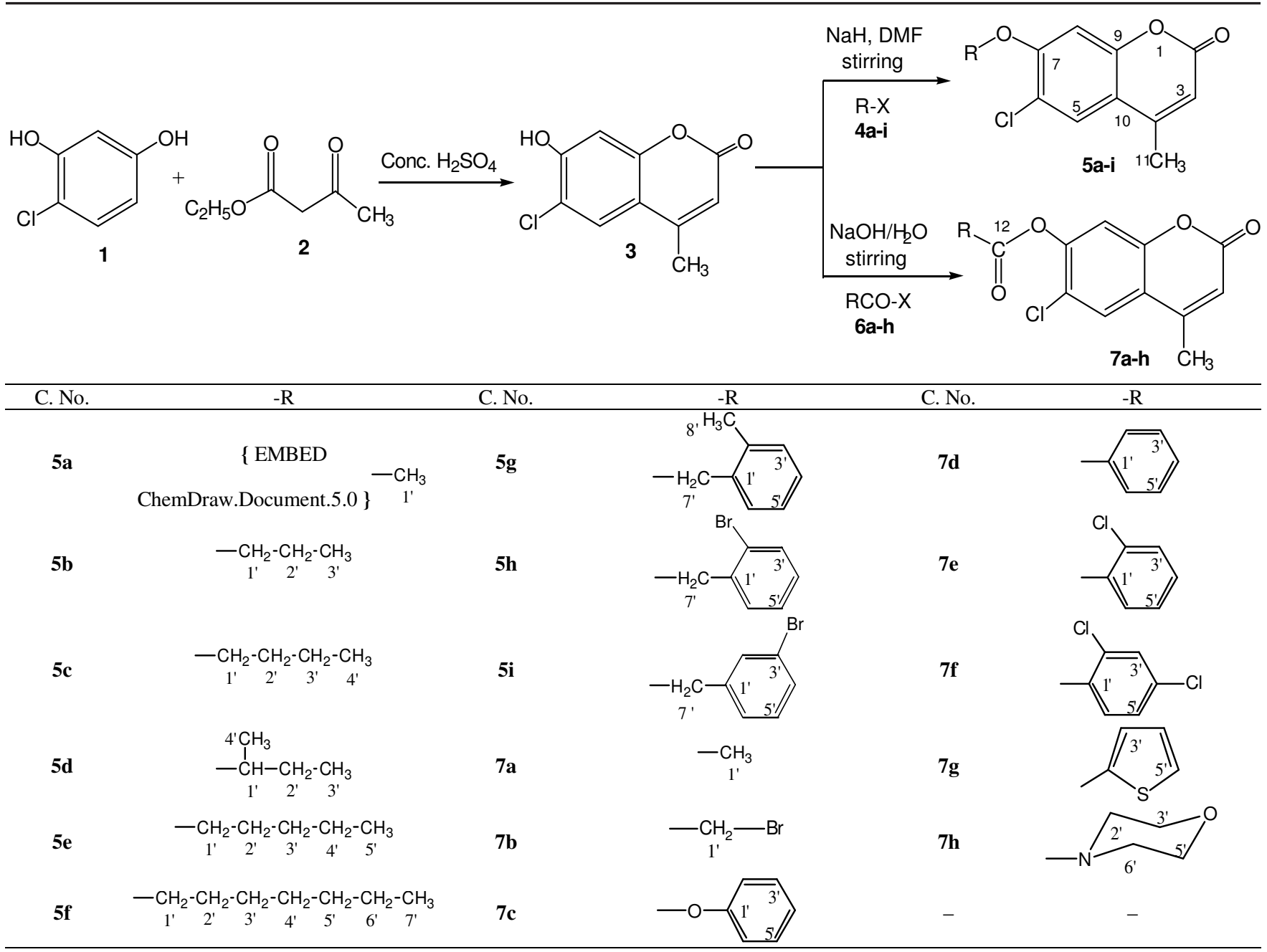

Scheme-I: Outline for the synthesis of 7-O-alkyl/aralkyl/acyl-substituted derivatives of chlorinated coumarin

The precipitates of the finalized products were afforded by filtration after the addition of the ice cold distilled water. Similarly, the compound $\mathbf{3}$ was reacted with acyl halides in the presence of basic medium of $10 \% \mathrm{NaOH}$. The reaction contents were further stirred for $25 \mathrm{~min}$. The precipitates were obtained through filtration and washing was carried out by distilled water. The antibacterial activity of the two series having ether and ester linkage, respectively of synthesized compounds was processed against certain bacterial strains along with structure elucidation through spectral data. The compound $\mathbf{3}$ was synthesized as light brown amorphous solid which showed three ${ }^{1} \mathrm{H}$ NMR signals at $\delta 7.54(\mathrm{~s}, 1 \mathrm{H}, \mathrm{H}-5), 6.98(\mathrm{~s}, 1 \mathrm{H}, \mathrm{H}-8)$ and $6.17(\mathrm{~s}, 1 \mathrm{H}, \mathrm{H}-3)$ corresponding to three methine protons and at $\delta 2.37\left(\mathrm{~s}, 3 \mathrm{H}, \mathrm{CH}_{3}-11\right)$ which showed one methyl group present in the molecules. In the ${ }^{13} \mathrm{C}$ NMR (BB and DEPT) spectrum, the ten signals were appeared corresponding to six quaternary, three methine and one methyl carbons. The six quaternary signals at $\delta_{\mathrm{C}} 160.5(\mathrm{C}-2), 157.7$ (C-7), 153.4 (C-4), 151.5 (C-9), 118.7 (C-6) and 113.6 (C-10); three methine signals at $\delta_{\mathrm{C}} 125.4(\mathrm{C}-5), 112.7(\mathrm{C}-3)$ and $100.3(\mathrm{C}-8)$ and one methyl signal appeared at $\delta_{\mathrm{C}} 18.5(\mathrm{C}-11)$.

The compound $\mathbf{5 h}$ was synthesized as a white amorphous solid having $78 \%$ yield and m.p. $110-112^{\circ} \mathrm{C}$. The m.f. $\mathrm{C}_{17} \mathrm{H}_{12} \mathrm{BrClO}_{3}$ was based on EI-MS with $[\mathrm{M}]^{+}$ion peak at $m / z 379,{ }^{1} \mathrm{H}$ NMR spectrum showing the protons and ${ }^{13} \mathrm{C}$ NMR spectrum showing the carbon atoms. The IR spectrum depicted the major absorption bands at 3050, 1725 and $1626 \mathrm{~cm}^{-1}$ because of $\mathrm{C}-\mathrm{H}$ aromatic stretching, stretching of $\alpha, \beta$-unsaturated $\mathrm{C}=\mathrm{O}$ and stretching of aromatic $\mathrm{C}=\mathrm{C}$ in the molecule. The mass spectrum showed two peaks at $m / z 210$ and 171 related to the coumarin cation and the 2-bromobenzyl cation fragments of the molecule, respectively. In ${ }^{1} \mathrm{H}$ NMR spectrum, the signals were appeared at $\delta 7.60(\mathrm{~s}, 1 \mathrm{H}, \mathrm{H}-5), 6.90(\mathrm{~s}, 1 \mathrm{H}, \mathrm{H}-8), 6.16$ (s, 1H, H-3) and 2.37 (s, 3H, $\left.\mathrm{CH}_{3}-11\right)$ were attributed to 6-chloro7-hydroxy-4-methyl-2H-chromen-2-one (3). The substitution of 2-bromobenzyl group was corroborated via five signals at $\delta 7.57$ (brs, 1H, H-3'), 7.55 (brs, 1H, H-6'), 7.34 (t, $J=7.2 \mathrm{~Hz}$, $\left.1 \mathrm{H}, \mathrm{H}-5^{\prime}\right), 7.22$ (t, J = 7.2 Hz, 1H, H-4') and 5.24 (s, 2H, H-7') in ${ }^{1} \mathrm{H}$ NMR spectrum assigned to four protons of aromatic ring and two protons of methylene group attached to oxygen of chlorinated coumarin. From ${ }^{13} \mathrm{C}$ NMR (BB and DEPT), the two signals (with single intensities) showing appearance at $\delta_{\mathrm{C}}$ 134.5 and 119.3 were assigned to two quaternary carbons (C-1' and C-2', respectively); four signals appearing at $\delta_{\mathrm{C}} 132.7$, 129.6, 128.6 and 127.7 with single intensities were related to four methine carbons (C-3', C-6', C-4' and C-5', respectively); and one signal of methylene carbon $\left(\mathrm{C}^{-} \mathrm{7}^{\prime}\right)$ with single intensity at $\delta_{\mathrm{C}} 70.4$ confirmed the attachment of aralkyl group. On the ground of all above accumulative data, the structure of $\mathbf{5 h}$ as confirmed as 6-chloro-7-((2-bromophenyl)methoxy)-4-methyl- 


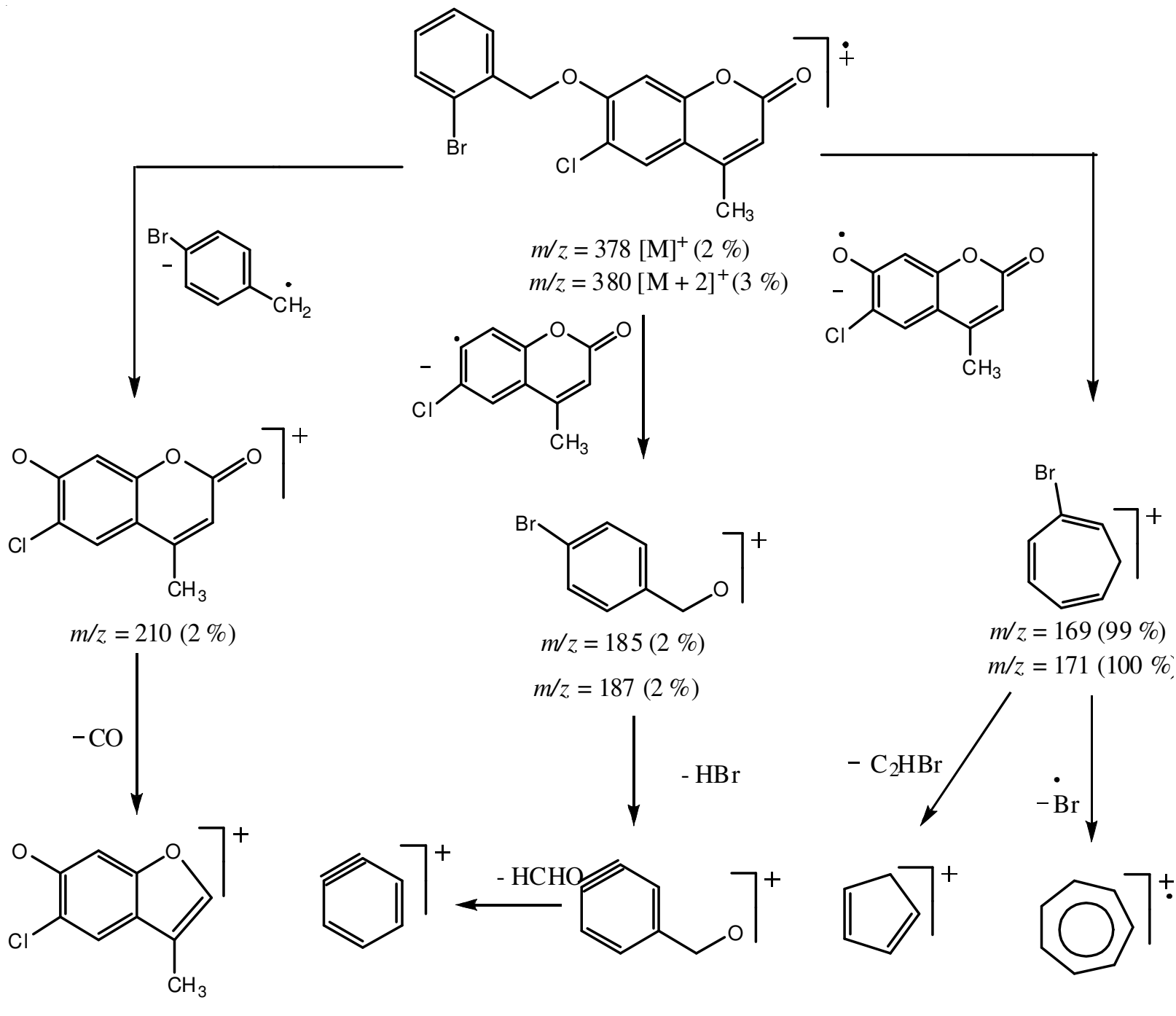

$$
m / z=181(6 \%) \quad m / z=75(6 \%) \quad m / z=105(5 \%) \quad m / z=65(4 \%) \quad m / z=90(65 \%
$$

\begin{tabular}{|c|c|c|c|c|c|c|}
\hline \multicolumn{7}{|c|}{$\begin{array}{c}\text { TABLE-1 } \\
\text { ANTIBACTERIAL ACTIVITY OF THE SYNTHESIZED COMPOUNDS }\end{array}$} \\
\hline \multirow[b]{2}{*}{ Compound } & \multicolumn{6}{|c|}{ MIC } \\
\hline & $\begin{array}{c}\text { Basillus subtilis } \\
(+)\end{array}$ & $\begin{array}{l}\text { Staphylococus } \\
\text { aureus }(+)\end{array}$ & $\begin{array}{c}\text { E. coli } \\
(-)\end{array}$ & $\begin{array}{l}\text { Shigella sonnei } \\
(-)\end{array}$ & $\begin{array}{l}\text { Salmonella typhi } \\
(-)\end{array}$ & $\begin{array}{l}\text { P.aureginosa } \\
\quad(-)\end{array}$ \\
\hline 5a & $8.43 \pm 0.42$ & $19.14 \pm 0.17$ & $7.52 \pm 0.14$ & $13.37 \pm 0.27$ & $11.01 \pm 0.22$ & $13.06 \pm 0.12$ \\
\hline $\mathbf{5 b}$ & $8.88 \pm 0.24$ & $7.42 \pm 0.16$ & $11.05 \pm 0.10$ & $13.01 \pm 0.18$ & $15.03 \pm 0.27$ & $14.18 \pm 0.34$ \\
\hline $5 \mathbf{c}$ & - & - & - & - & - & - \\
\hline 5d & $10.00 \pm 0.41$ & $11.03 \pm 0.09$ & $17.91 \pm 0.11$ & $18.3 \pm 0.05$ & $15.18 \pm 0.17$ & $14.42 \pm 0.05$ \\
\hline $5 e$ & - & - & - & - & - & - \\
\hline $5 f$ & - & - & - & - & - & - \\
\hline $5 g$ & - & - & - & - & - & - \\
\hline $5 \mathrm{~h}$ & $7.78 \pm 0.11$ & $6.50 \pm 0.29$ & $9.61 \pm 0.08$ & $13.01 \pm 0.11$ & $14.17 \pm 0.26$ & $14.27 \pm 0.06$ \\
\hline $5 i$ & $8.402 \pm 0.18$ & $6.57 \pm 0.12$ & $8.84 \pm 0.41$ & $14.66 \pm 0.22$ & $11.19 \pm 0.31$ & $15.30 \pm 0.17$ \\
\hline $7 a$ & - & - & - & - & - & - \\
\hline $7 b$ & - & - & - & - & - & - \\
\hline $7 c$ & - & - & - & - & - & - \\
\hline 7d & - & - & - & - & - & - \\
\hline $7 e$ & - & - & - & - & - & - \\
\hline $7 f$ & - & - & - & - & - & - \\
\hline $7 \mathrm{~g}$ & - & - & - & - & - & - \\
\hline $7 \mathrm{~h}$ & - & - & - & - & - & - \\
\hline Ampicillin & $13.92 \pm 0.29$ & $11 \pm 0.01$ & $11.32 \pm 0.13$ & $13.11 \pm 0.11$ & $12.78 \pm 0.21$ & $16.86 \pm 0.31$ \\
\hline Ciprofloxacin & $8.96 \pm 0.02$ & $8.12 \pm 0.21$ & $8.22 \pm 0.12$ & $11.34 \pm 0.02$ & $8.19 \pm 0.01$ & $10.03 \pm 0.1$ \\
\hline
\end{tabular}

Fig. 1. Mass fragmentation pattern of 6-chloro-7-((2-bromophenyl) methoxy)-4-methyl-2H-chromen-2-one (5h) 
$2 \mathrm{H}$-chromen-2-one. The mass fragmentation pattern of $\mathbf{5 h}$ was clearly outlined in Fig. 1.

Antibacterial activity: The results of two series of compounds against certain bacterial strains are tabulated in Table-1. An overview of the results proved that the alkylated derivatives of chlorinated coumarin were more active against the clinically isolated bacteria (Gram-positive and Gram-negative) than the acylated derivatives. Among the active compounds, 5a, 5b, $\mathbf{5 d}, \mathbf{5 h}$ and $\mathbf{5 i}$, all showed better activity potential against all the bacterial strains. Some of them were more active against the bacteria with respect to the standard ampicilin and ciprofloxacin. The active five compounds have the small aliphatic chain in common. The two compounds, $\mathbf{5} \mathbf{h}$ and $\mathbf{5 i}$, have aromatic ring substituted by halogen and showed good activity. $\mathbf{5 b}$ and $\mathbf{5 d}$ were less active than the ciprofloxacin but showed almost same activity relative to Ampicilin against all the bacterial strains. All the five active compounds showed relatively less activity than Ciprofloxacin but almost the same activity relative to ampicilin against the three Gram-negative bacteria.

\section{Conclusion}

The synthesized compounds were affirmed by spectral data. From the Table-1, its clear that all the derivatives having small aliphatic chains were active against all the strains of gram +ve and gram -ve bacteria.

\section{ACKNOWLEDGEMENTS}

The authors are grateful to HEC Pakistan for fiscal aid.

\section{REFERENCES}

1. A. Behrami and I. Krasniqi, Res. J. Pharm. Biol. Chem. Sci., 3, 369 (2012).

2. A.A. Al-Rifai, M.T. Ayoub, A.K. Shakya, K.A. Abu Safieh and M.S. Mubarak, Med. Chem. Res., 21, 468 (2012).

3. N.N. Farshori, M.R. Banday, A. Ahmad, A.U. Khan and A. Rauf, Med. Chem. Res., 20, 535 (2011).

4. Y. Shi and C.H. Zhou, Bioorg. Med. Chem. Lett., 21, 956 (2011)

5. S.M. Naik and H.B. Naik, Asian J. Chem., 11, 1540 (1999).

6. K.N. Venugopala and B.S. Jayashree, Asian J. Chem., 16, 407 (2004).

7. O. Alam, S.K. Gupta, M. Imran and S.A. Khan, Asian J. Chem., 17, 1281 (2005).

8. K.N. Venugopala, B.S. Jayashree and M. Attimarad, Asian J. Chem., 16(2), 872 (2004)

9. P. Desai, A.C. Champaneri and K.R. Desai, Asian J. Chem., 12, 1327 (2000).

10. Aziz-ur-Rehman, S. Rasool, M.A. Abbasi, K.M. Khan, M. Asraf and I. Afzal, Asian J. Phram. Biol. Res., 2, 100 (2012).

11. M. Kaspady, V.K. Narayanaswamy, M. Raju and G.K. Rao, Lett. Drug Des. Discov., 6, 21 (2009).

12. C.-R. Yang, Y. Zhang, M.R. Jacob, S.I. Khan, Y.-J. Zhang and X.-C. Li, Antimicrob. Agents Chemother, 50, 1710 (2006). 